\title{
Identification nonpolar component and antibacterial activities of Iophon laevistylus from Persian Gulf
}

\author{
Melika Nazemi, Zhaleh Khoshkhoo, Abbasali Motalebi, Hosseinali Karimi Firozjaee and Fatemeh \\ Pishehvarzad
}

\begin{abstract}
In this investigation of Iophon Laevistylus, collected from Faro Island in Persian Gulf, was extracted of polar and nonpolar contents using the method of Bligh \& Dyer. Methanolic and diethyletter were used as extraction solvents, after removal of the solvents, the GC/MS spectra of the fraction were obtained. Identification of constituents was made by comparison of their mass spectra and retention indices (RI) with those given in the literature and authenic samples. 19 components respecting $95 \%$ were identified carbohydrate. In vitro antibacterial screening, against selected clinical isolates of bacteria was conducted in this study. Methanolic and diethyletter extracts demonstrated activity against Escherichia coli and Bacillus subtilis microbes tested. MIC and MBC were determined using Bacterial Broth Dilution Methods. The extracts showing good antimicrobial activity are undergoing further analysis to identify the active constituents.
\end{abstract}

Index Terms - Iophon Laevistylus, MIC (minimum inhibitory concentration), $\mathrm{MBC}(\mathrm{minimum}$ bacterial concentrate), Antibacterial activity and Persian Gulf.

\section{INTRODUCTION}

Sponges, which constitute the phylum Porifera, are the most primitive of the multicellular animals neither true tissues nor organs are present, and the cells display a considerable degree of independence (Barnes, 1987). Of the approximately 15,000 sponge species, most occur in marine environments, Only about $1 \%$ of species inhibits in freshwater (Belarbi et al., 2003). Approximately 95\% sponges are classified as Demospongia (Zhang et al., 2003).

Among all marine organisms screened, marine sponges produce the largest number of structurally diversified natural products, which in fact represent the best source of marine bioactive compounds particularly for pharmaceutical leads (Zhang et al., 2003).

These natural products are metabolites that classified into two broad types, primary metabolites are essential to growth and life in all living systems, and are formed by a limited number of

Manuscript received April 10, 2010.

Melika Nazemi is with the Iranian Fisheries Research Organization, Tehran, Iran, P.O. Box 14155-6116 (corresponding author, phone: +98-912- 3612456 ; fax: +98-21-66514381; e-mail: melikanazemi@yahoo.com).

Zhaleh Khoshkhoo is with the Department of Fisheries, Facuty of Natural Resources, North Tehran Branch of Islamic Azad University, Tehran, Iran (e-mail: zhaleh khoshkhoo@yahoo.com).

Abbasali Motalebi, is with Iranian Fisheries Research Organization, Tehran, Iran, P.O. Box 14155-6116. (e-mail: motalebi@ifro.ir).

Hosseinali Karimi Firuzjaii is with Islamic Azad University of Rudehen Branch, Rudehen, Tehran, Iran. (e-mail: ha_karimi82@yahoo.com).

Fatemeh Pishehvarzad is with Guilan University, Iran (e-mail: Andishmand45@yahoo.com) metabolic reactions. Primary metabolites serve as building blocks for synthesis of macromolecules, proteins, nucleic acids, carbohydrates and lipids. Secondary metabolites are not essential to the life of producing organism and are formed by primary metabolites (Gudbjarnason, 1999).

The research for bioactive compounds in sponges began during the 1950s. Bergmann and co-workers, worked on the Caribbean sponge, Cryptothia crypta isolated a series of arabinosyl nucleosides of which the major was potent tumor inhibitor, spongouridine. After the discovery of spongouridine, a large number of compounds have been isolated from marine sponges (Nagabhushanam et al., 2004).

Hence, sponges have the potential to provide futures drugs against important diseases, such as cancer, arrange of viral diseases, malaria, inflammations and microbial. Many new molecules with antibiotic properties are discovered every year, but in marine sponges their ubiquity is remarkable (Sipkema et al., 2005).

In this research, we describe the screening of marine sponge extract collected from Faro Island in Persian Gulf, for antibacterial activity. This study is part of a programme on screening of marine organisms for a variety of biological activities, with the aim of identifying novel with interesting and potentially useful therapeutic activities.

\section{MATERIALS AND METHODS}

Samples were collected by scuba diving from sub tidal habitats at depths between 15 to $20 \mathrm{~m}$, from location on the coastline of Fro Island (southern Iran).They were frozen as soon as possible and transferred to the laboratory where they were extracted in solvent.

Taxonomic designation was based on scanning light microscope and on skeletal slides and dissociated spicule mounts. For calcareous spicules preparation used bleach digestion technique, small fragments of 'tissue' are place on microscopic glass slides. A small quantity of active bleach (sodium hypochlorite) is added to the fragment, and after a 5 minuets the organic components dissolve leaving only the mineral skeleton. The bleach diluted and washed with out of tissues several times, with water and ethanol. For siliceous spicules preparation used acid digestion technique. This process uses nitric acid instead of bleach. Small fragments of 'tissue' are place on microscopic glass slides. Several drops of acid are placed on fragment, gently heated over a flame until bubbling, and repeated until all organic matter is digested. Siliceous spicules are bonded directly onto the substrate by this technique, which makes useful for microscopy 
(Hooper, 2000).

The sample was collected in methanol about 24 hours, the polar extraction was produced. Then the sample put in diethyletter for 72 hours, The nonpolar extraction was produced (Bligh\& Dyer, 1959). After solution filtered and evaporating methanol to dryness, at low pressure at $45-55 \mathrm{C}$ by using Rota vapor. Concentration phases, essence analysis by GC/MS, then identification of the component, and finally the determination of antibacterial activities. The polar compounds in the phase of methanol-water were separated. The concentrated methanolic extracts was then dried to obtain crude semi-solid extracts. The crude extract was then weighted and percentages of extraction from sponge were calculated and then added DMS. After 72 hours evaporating diethyletter to dryness, at low pressure at 40-45 C by using Rota vapor. The concentrated diethyletter extracts was then dried to obtain crude semi-solid extract (Bligh\& Dyer, 1959).

Antibacterial activity was determined against Escherichia coli, Pseudomonas aeruginosa, Staphylococcus aureus, and Basilus subdilish using the Bacterial Broth Dilution Methods. To perform the classic broth dilution susceptibility test, a standard inoclum of the microorganism(e.g., organisms $1.5 * 105$ colony forming units[CFU]/ml, a 1:100 dilution of a suspension of turbidity equal to a McFarland standard 0.5 , was added to an equal volume $(1 \mathrm{ml})$ of each concentration of extracts agent and to a tube of the growth control. An uninoculated tube of medium was incubated to serve as a negative growth control. After overnight, the tubes were examined for turbidity, indicating growth control of the microorganism. The lowest concentration of the agent that inhibits growth of the organism, as detected by lack of visual turbidity ( matching the negative growth control), is designated the minimum inhibitory concentration(MIC).

After the MIC has been determined, a known quantity, $0.1 \mathrm{ml}$, of inoculums from each of the tubes of broth that showed on visible turbidity after 22 to 24 hours' incubation is sub cultured to solid agar plates. The number of colonies that grow on the subculture after overnight incubation is then counted and compared to the number of $\mathrm{CFU} / \mathrm{ml}$ in the original inoclum. Since even bacterial extracts do not always totally sterilize a bacterial population, the lowest concentrate of antimicrobial agent that allowed less than $0.1 \%$ of the original inoculums to survive is said to be the minimum bacterial concentrate(MBC) (Rodrigues, 2004).

\section{RESULtS}

This sample is tube- shape sponge (Fig.I), and was growing on stone and hard substrate. The calcareous spicules were identified, the megascleres were monoaxon, rhabd,(Fig.II), the length was varied between $70-90 \mu \mathrm{m}$. The siliceous spicules were identified too, they were monoaxon but in different shapes, rhabd and root spicules. the length of root spicuLes was varied between 50-90 $\mu \mathrm{m}$, and rhabd was $20-90 \mu \mathrm{m}$ (Fig.III).Identification was carried by key of sponguide, John.N.A.Hooper, therefore assignment of the present species to the class Demospongia, order Poecilosclerida, suborder Microcionina, family Iophonidae, genus Iophon Laevistylus .

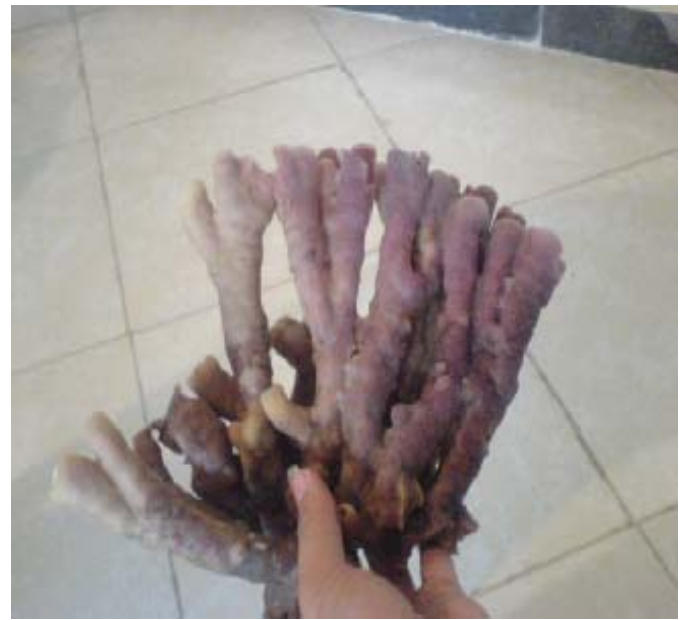

FigureI. Iophon Laevistylus.

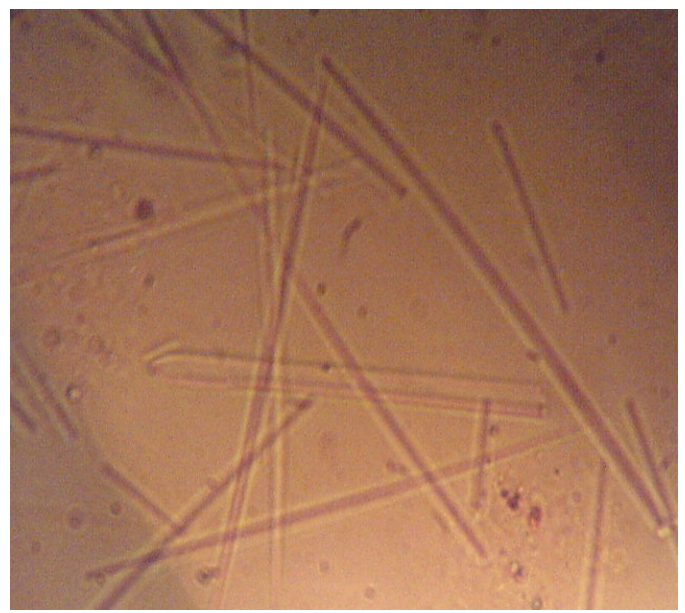

Figure II. The calcareous spicules in the light microscope.

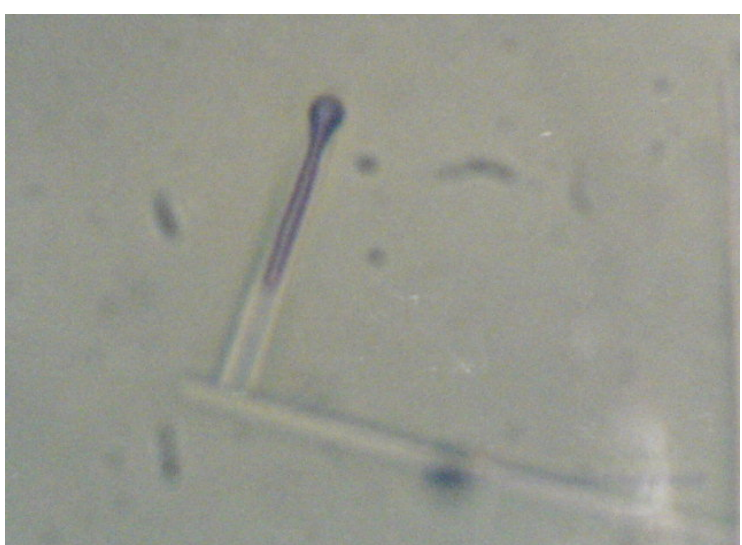




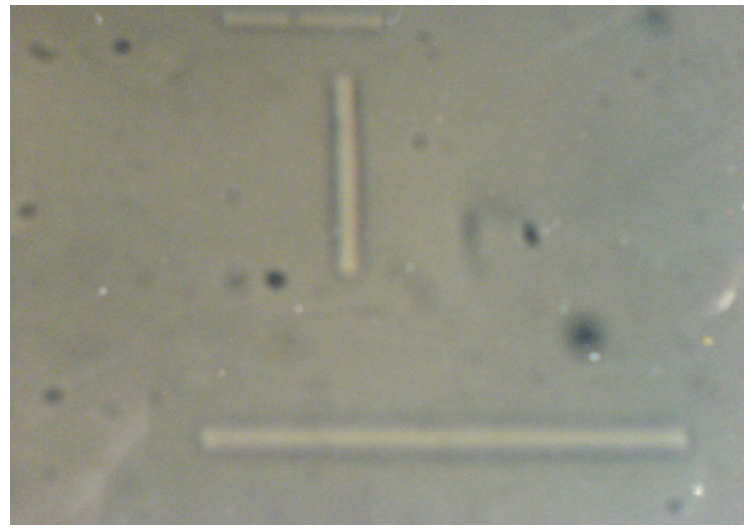

FigureIII. The siliceous spicules in the light microscope.

The Alpha- Pinene(1), Sabinene(2), beta- Cymene(3), 1-1-Limonene(4), hendecane(5), Alpha. Fenchyl Alcohol(6), Endo- Borneol(7), Alpha- Terpineol(8), Verbenone(9), Naphthalene, 2-methyldodecane(10), Tridecane(11), Tridecane, 2- methyl, Tetradecane, Valencene(12), Pentadecane(13), Hexadecane(14), n- Octadecane(15), 1- methyl tetradecanoate, and Palmitic acid(16) was isolated from Iophon Laevistylus

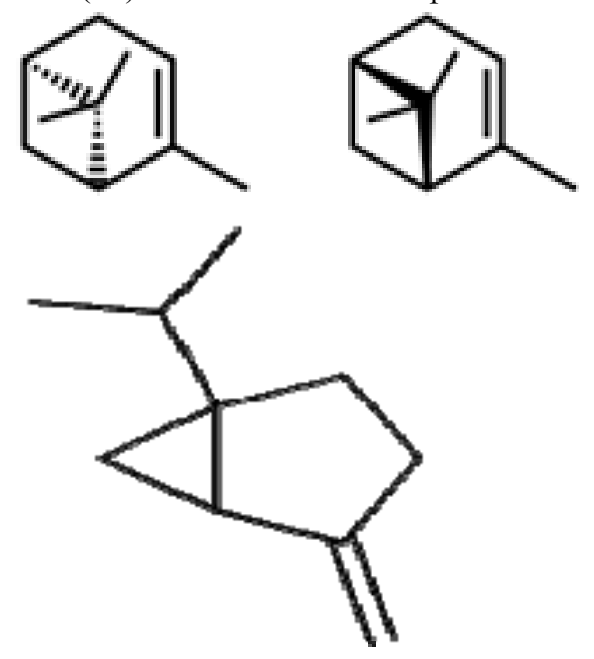

(1)

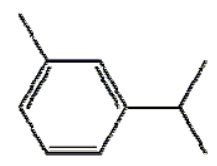

(2)

(3)

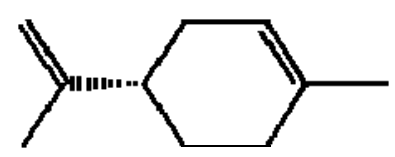

(4)<smiles>CCCCCCCCCCCC</smiles>

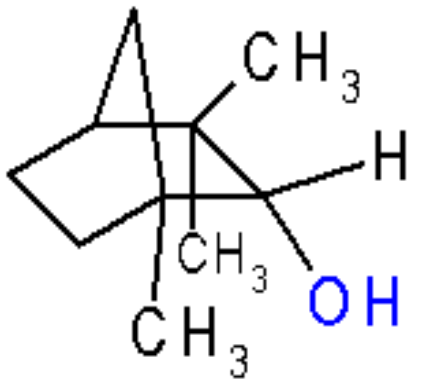

(6)
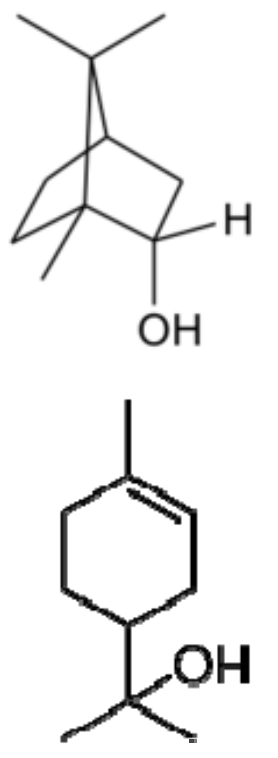

(8)

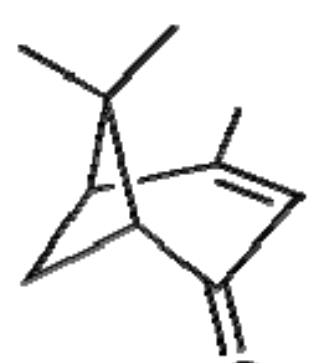

(9)
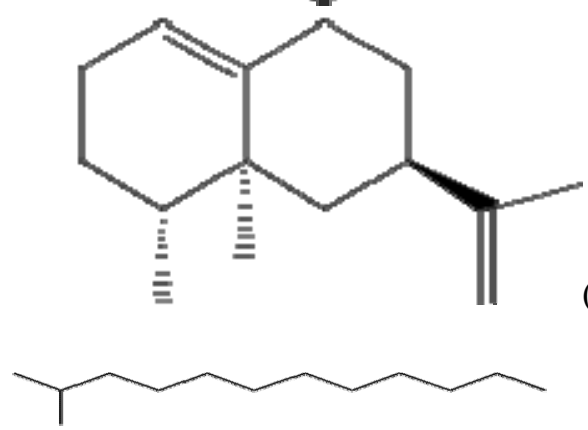

(5)

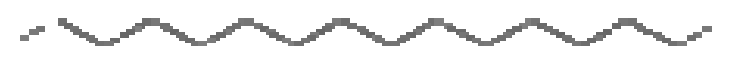




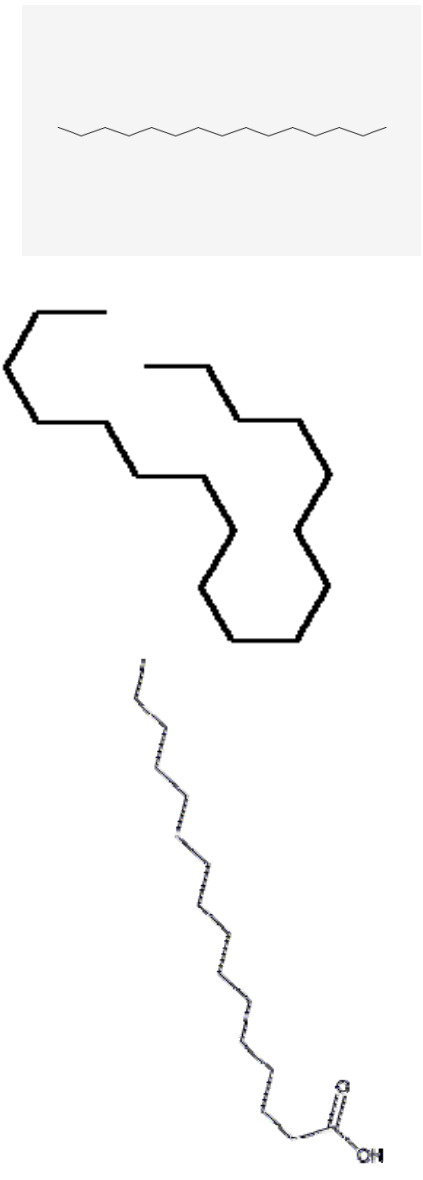

The results show, the organic extracts(Methanolic, diethyletter and water) from Iophon laevistylus do not have exhibited activity against Pseudomonas aeruginosa, but Methanolic and diethyletter extracts exhibited activity against Staphylococcus aureus, Basilus subdilish and Escherichia coli. Methanolic extracts good bactericidal activity against Escherichia coli, Basilus subdilish and Staphylococcus aureus. As a result from turbidity the most activity against our pathogenic bacteria is methanolic extracts $(\mathrm{MIC}=1.5 \mathrm{mg})$, then diethyletter extracts $(\mathrm{MIC}=2 \mathrm{mg})$ and water extracts did not have bactericidal activity.

The methanolic extraction exhibited antibacterial activity against gram positive bacteria (Escherichia coli and Basilus subdilish) (Table 1). Although potent antibacterial of methanol extraction on Escherichia coli, $\mathrm{MBC}=2 \mathrm{mg} / \mathrm{ml}$, and potent antibacterial of diethyletter extraction on Escherichia coli, MBC was $3 \mathrm{mg} / \mathrm{ml}$. Potent antibacterial of methanol extraction on Basilus subdilish ,MBC was $3 \mathrm{mg} / \mathrm{ml}$, and potent antibacterial of diethyletter extraction on Basilus subdilish, MBC was $3 \mathrm{mg} / \mathrm{ml}$.

\section{Extraction $\quad$ Bacteria Number of colony}

$\begin{array}{lll}\text { Methanol (2mg) } & \text { Escherichia coli } & 0 \\ \text { Diethyletter (3mg) } & \text { Escherichia coli } & 0 \\ \text { Methanol (3mg) } & \text { Basilus subdilish } & 0 \\ \text { Diethyletter (3mg) } & \text { Basilus subdilish } & 0\end{array}$

Tanle1. Identified MBC from extractions

\section{DisCUSSION}

Persian Gulf is a rich source of marine organisms, have become a leading source of bioactive marine products and are known to produce large amounts of secondary metabolites. Sponges have provided more marine natural products than any other phylum, due in part to their propensity to produce bioactive metabolites (Faulkner, 2002). In our study about 20 components were isolated from Iophon laevistylus which related to carbohydrates (terpenes) and saturated fatty acid. In other study demonstrated structural classes, notably terpens, polyketides and alkaloids (Blackman, 2005).

The novel antibiotics are present in marine bacteria, tunicates, sea hares, soft corals, algae, sponges, worms and fish. Many new molecules with antibiotic properties are discovered every year, but in marine sponges their ubiquity is remarkable (Rodrigues, 2004). In this investigation, on extraction of Iophon laevistylus from porifera, the water extraction does not have any antibacterial activities. But methanol and diethyletter have good potential antibacterial activity against microbes, such as Escherichia coli and Basilus subdilish. Sponges have different biological activity, same as antimicrobial activities. Global researches showed variety activities against bacterial. In the different investigation on sponges extracts shows antibacterial activities on Staphylococcus aureus, Escherichia coli, Bacteroides fragilis, Bacteroides thetaiotaomicron and mycobacteria Mycobacterium tuberculosis (Hedner, 2008\& Rodrigues, 2004).

In our study Iophon laevistylus which collected from Faro Island in Persian Gulf had been shown possess a bactericidal activity. This is the first report of the antimicrobial activity from sponges in Iran. Furthermore, the encouraging biological activities seen in this study showed that the Persian Gulf coastline has a potential source of variety in marine organisms, specially sponges, that worth for further investigation.

\section{ACKNOWLEDGMENT}

Special thanks to personnel and experts of the laboratory of Iranian Fisheries Research Organization, and all the person who help us in this project .

\section{REFERENCES}

[1] Barnes Robert D. 1987. Invertebrate Zoology, Elviser, 878

[2] Belarbi El Hassan, Antonio Contreras Gomez, Yosuf Chisti, Francisco Garcia and Emilina Molina Grima. 2003. Producing drugs from marine sponges. Biotechnology Advances , 21: 585-598.

[3] Zhang Wei, Song Xue, Quanyu Zhao, Xiaoying Zhang, Jinhe Li, Meifang Jin, XingYu and Quan Yuan, 2003. Biotpotentials of marine sponges from China Oceans: Past and future. Biomolecular Engineering, 20: 413-419.

[4] Gudbjarnason Sigmundur,1999. Bioactive marine natural products. Rit Fiskiderldar, 16: 107-110.

[5] Sipkema Detmer, Maurice C.R.Franssen, Ronald Osings, Johnnes Tramper and Rene H.Wijffels. 2005. Marine Sponges as Pharmacy. Marine Biotechnology, 17:142-162.

[6] Nagabhushanam R., Diwan A.D, Zahurance B.J and Sarojini R, 2004. Biotechnology of Aquatic Animals, Oxford \& IBH Publishing CO. Pvt.Ltd, New Dehli, 2end edition :276.

[7] Hooper John N.A, 2000.

[8] SPONGUIDE.Queensland Museum, Australia.

[9] Hedner Erik. 2008. Bioactive Compounds in the Chemical Defence of Marine sponges. UPPSALA UNIVERSITY, 245.

[10] Rodrigues Ely, Supriya Tilvi and Naik C.G, 2004. Antimicrobial activity of marine organisms collected off coast of South East India. Experimental Marine Biology and Ecology, 309:121-127.

[11] Blight E.G, and Dyer W. J, 1959. Can. Biochemistry and physiology.

[12] Faulkner John. 2002. Marine natural products. The Royal Society of Chemistry, 19: 1-48.

[13] Blackman, A. J, 2005. Biosynthesis and Function of natural products laboratory manual. University of Tasmania, Hobart. 